\title{
Does Pain and Fatigue Interfere in the Independence of People with Incomplete Spinal Cord Injury?
}

Fernández SA ${ }^{1}$, Gatti MA ${ }^{1 *}$, Buffetti $E^{1}$, Freixes $\mathrm{O}^{1}$, Bonetto $\mathrm{M}^{2}$, Waldman SV ${ }^{3}$, Rivas $\mathrm{ME}^{1}$, Russo $\mathrm{MJ}^{3}$, Gath $\mathbf{C F}^{\mathbf{1}}$ and Olmos $\mathbf{L E}^{\mathbf{3}}$

${ }^{1}$ Physical Therapy Unit, FLENI Rehabilitation Institute, Buenos Aires, Argentina

${ }^{2}$ Occupational Therapy Unit, FLENI Rehabilitation

Institute, Buenos Aires, Argentina

${ }^{3}$ Departament of Rehabilitation Medicine, FLENI

Rehabilitation Institute, Buenos Aires, Argentina

*Correspondling author: Marcelo Andrés Gatti, Physical Therapy Unit, FLENI Rehabilitation Institute, Ruta 9 Km 52.5, Colectora Este, Escobar, Buenos Aires, Argentina

Received: J une 30, 2018; Accepted: August 03, 2018; Published: August 10, 2018

\begin{abstract}
Objectives: The aim of this study is to determine the impact of pain and fatigue on activities of daily life in subjects with motor-incomplete spinal cord injury $(\mathrm{SCl})$.

Methods: This study included a sample of 74 subjects with motorincomplete $\mathrm{SCl}$. The sample was divided in two groups according the leve of pain in the visual analogue scale (VAS). Also, the sample was divided in two groups by the score of the fatigue severity scale (FSS). We compared the functional independence measurement (FIM) median values between the groups. Normality of data was assessed using the Shapiro-Wilks Test before choosing a non-parametric test. Man Whitney or Median Test was used according to variable's distribution shapes
\end{abstract}

Results: Significant fatigue was reported in 22 participants $(30 \%)$, who present a median FIM motor score of 80 . Fifty two subjects $(70 \%)$ did not report fatigue, with a median score of 83 . There were no significant differences found among the groups in the FIM motor score $(p 0.874)$. Significant pain was reported in 25 participants (34\%), who present a median FIM motor score of 80 . Forty nine subjects $(66 \%)$ did not report pain, with a median score of 83 . There were no significant differences found among the groups in the FIM motor score (p 0.363).

Conclusion: Pain and fatigue are relatively prevalent symptoms in subjects with motor incomplete $\mathrm{SCl}$; however, these symptoms did not interfere with our participant's ability to perform activities of daily living independently.

Keywords: Fatigue; Pain; Spinal cord injury; FIM; Daily life activities

\section{Introduction}

Pain and fatigue are two health conditions common in people with neurologic disorders, like Multiple Sclerosis, Parkinson's disease, stroke [1-4], and spinal cord injury (SCI) [5]. They are associated with physical impairment and reduce capacity to participate in daily activities, affecting quality of life [6-9]. In people with Spinal cord injury, both symptoms are frequent and lead to negative health results. Also, pain is a potentially important covariate of fatigue $[5,10]$.

Fatigue is a symptom described as an overwhelming sense of tiredness, lack of energy and feeling of total exhaustion, and has been studied in people with SCI [5,6,10-12]. Fatigue has a negative impact on physical ability, and compromises the ability to participate in daily life activities, thus reducing the quality of life [13]. A study by FawkesKirby [5] fatigue is present in up to $57 \%$ of patients with myelopathies and is more common in patients with incomplete injuries, presenting as a symptom that interferes with activity [14]. Similarly, pain is also a common symptom among individuals with disabilities, including SCI [5,9]. After SCI, overall pain rates range from $25 \%$ to $96 \%$, and severe pain is reported by $18-63 \%$ of individuals $[13,15,16]$. With regard to physical functioning, pain has been reported to interfere with everyday activity on an average of 16 out of 90 days [17] and has a number of negative consequences including effects on ability to fall asleep (58\%), exercise (35\%), do household chores (39\%), and work outside the home (34\%) [18] among persons with SCI. Due to ongoing advances in basic science and locomotor rehabilitation research, there has been an increase in incomplete SCI lesions [19]. Fawkes-Kirby et al. described higher levels of fatigue in this specific population. Although pain and fatigue have received a great deal of attention in the research literature, the impact of these symptoms on activities of daily life (ADLs) in incomplete motor SCI has yet not been study. Therefore, the purpose of this study is to determine the impact of pain and fatigue on ADLs in incomplete motor SCI. We hypothesized that both symptoms would interfere with participant's ability to perform activities of daily living independently.

\section{Materials and Methods}

\section{Design}

Transversal cohort.

\section{Participants}

Patients with Asia Impairment Scale (AIS) C and D were identified in our database and were contacted and prospectively included for the analysis. Participation in the study was voluntary. Inclusion criteria were: motor incomplete SCI (AIS C or D), aged $\geq 18$ years and at least 12 months of injury evolution with a stable medical condition. All participants included in the study were previously inpatients or outpatients in the SCI rehabilitation program at FLENI Escobar 
Table 1: Demographic Characteristics.

\begin{tabular}{|c|c|c|c|c|c|c|}
\hline & No Fatigue & Fatigue & $p$-value & No Pain & Pain & $p$-value \\
\hline \multicolumn{7}{|l|}{ Gender, n (\%) } \\
\hline Female & $15(57.7)$ & $11(42.3)$ & & $14(53.8)$ & $12(46.2)$ & \\
\hline Male & $37(77.1)$ & $11(22.9)$ & 0.081 & $35(72.9)$ & $13(27.1)$ & 0.098 \\
\hline \multicolumn{7}{|l|}{ Age, Year } \\
\hline Median (IQI) & $39(26.5-56.50$ & $51.5(35.5-63.7)$ & $0.021^{*}$ & $39(29-56)$ & $46(31-69.5)$ & 0.101 \\
\hline \multicolumn{7}{|c|}{ Level of Injury; n (\%) } \\
\hline Cervical & $26(68.4)$ & $12(31.6)$ & & $25(65.8)$ & $13(34.2)$ & \\
\hline Toracic-Lumbar & $26(72.2)$ & $10(27.8)$ & 0.721 & $24(66.7)$ & $12(33.3)$ & 0.936 \\
\hline \multicolumn{7}{|l|}{ ASIA, n (\%) } \\
\hline C & $22(68.8)$ & $10(31.2)$ & & $24(75)$ & $8(25)$ & \\
\hline $\mathrm{D}$ & $30(71.4)$ & $12(28.6)$ & 0.803 & $25(59.5)$ & $17(40.5)$ & 0.163 \\
\hline \multicolumn{7}{|c|}{ Time of injury, months } \\
\hline Median (IQI) & $44.5(22.2-64.7)$ & $35.5(19.2-63.5)$ & 0.836 & $32(21.5-64.50$ & $52(24-66)$ & 0.401 \\
\hline \multicolumn{7}{|l|}{ Occupation, hours } \\
\hline Median (IQI) & $25(10.5-40)$ & $15(0-40)$ & 0.756 & $27(11-40)$ & $20(0-38.5)$ & 0.327 \\
\hline \multicolumn{7}{|c|}{ Physical Activity, hours } \\
\hline Median (IQI) & $4(2.2-6.7)$ & $4.5(2-6.5)$ & 0.886 & $4(2.5-9)$ & $4(2-5.5)$ & 0.415 \\
\hline
\end{tabular}

N: Number; \%: Percentage; IQI: Interquartil Interval.

Man-Whitney Test or Median Test was used according to distribution groups in continuous variable.

Chi-square Test was used for categorical variables.

*Statistically significant difference at the $p<0.05$

Institute between 2007 and 2016. The exclusion criteria were inability to provide informed consent, inability to read and write in Spanish, pre-existing medical conditions, including demyelinising disease, previous SCI, or other neurological system illnesses and trauma, or chronic medical conditions such as diabetes, hypertension, and autoimmune disease.

Every subject had to sign the informed consent for the study. This study was approved by the Ethics Committee of FLENI.

\section{Data collection}

All eligible persons were identified and their email addresses and phone numbers were obtained from the FLENI Institution database. Subjects were contacted by telephone or email to agree to participate in the study. After consent was obtained the participants were enrolled in the study. Demographic data and different evaluations were administered by a physical therapist and an occupational therapist with at least 10 years experience in SCI rehabilitation.

\section{Measures}

Demographic and injury related data: Variables collected included general demographic information (age, sex, physical activity and hours worked) and injury related information (AIS classification, injury level and time of injury).

Functional independence measurement (FIM): The (FIM) assesses the level of independence of the patients [20,21]. In the present study, the motor score of the FIM was used consisting of thirteen items, scored on a seventh-point scale, varying from total assistance (one) to complete independence (seven) with a maximal score of ninety one [22].
Fatigue (FSS): The FSS is a validated questionnaire administered in these subjects, and has been used to appraise fatigue levels over the past week of the day of the questionnaire [23]. The nine-item FSS is a self-report scale that is used widely to assess disabling fatigue in individuals with neurological disorders. It has been shown to be valid and reliable in SCI population [24]. The FSS assesses the severity of fatigue. The FSS requires respondents to rate each item using a seven-point scale ranging from one (completely disagree) to seven (completely agree). The items were summed and a mean score was calculated. Higher scores indicate a higher severity of fatigue. A cutoff point of four is used to determine significant fatigue [25]. The scale is obtained through a self report questionnaire. A Spanish version of the FSS scale was used [14].

Pain: The Visual Analogue Scale (VAS) from zero (no pain) to ten (extreme pain) was used. This scale measure the average of the intensity global pain reported by the subject over the past week of the day of the questionnaire. A cut-off point of four is used to determine significant pain [26].

\section{Data analysis}

Descriptive statistics were calculated to analyze the subject's demographics and clinical characteristics (Table 1). Chi-square Test for categorical or Non-parametric test for continuous outcomes was used to analyze demographics characteristics of the different groups. Normality of data was assessed using the Shapiro-Wilks Test before choosing a non-parametric test. Man Whitney Test or Median Test was used according to variable's distribution shapes.

The sample was divided in two groups according the level of pain in the VAS. Those participants that had a score more or equal 4 were 
included in the pain group and those with less 4 were considered as no pain. Also, the sample was divided in two groups by the score of the Fatigue severity scale (FSS). Those participants that present a FSS more or equal 4 were considered as fatigue group, while those participants that present a FSS less 4 were considered as no fatigue group. We compared the FIM median values between the groups. Normality of data was assessed Shapiro-Wilks Test before choosing a non-parametric test. Median Test was used according to variable's distribution shapes. The results were expressed as median and interquartile range. A level of significance of 0.05 was established. All the analysis was calculated in SPSS 21 statistics program.

\section{Results}

\section{Participants}

A total of 117 patients with AIS C or D SCI were eligible for inclusion, 35 were not available at the time of the study, 7 chose not to participate and one patient died prior to inclusion. Of the 74 participants included for analysis, $65 \%(n=48)$ were male; the median age was 44 years ( $\mathrm{SD}=17.02$; range: $20-78)$ and the median time of injury was forty-one months. See Table 1 for additional demographics and AIS characteristic data.

\section{Fatigue}

Significant fatigue was reported in 22 participants (30\%), who present a median FIM motor score of 80 . The mean FSS value for this group was 4.59 . Fifty two subjects (70\%) did not report fatigue, with a median FIM motor score of 83. The mean FSS value for this group was 2.34. There were no significant differences found among the groups in the FIM motor score ( $p$ 0.874). See table 2 .

\section{Pain}

Significant pain was reported in 25 participants (34\%), who present a median FIM motor score of 80 . The mean pain value for this group was 5.88 . Forty nine subjects $(66 \%)$ did not report pain, with a median FIM motor score of 83 . The mean pain value for this group was 0.47 . There were no significant differences found among the groups in the FIM motor score ( $p$ 0.363) (Table 2).

\section{Discussion}

To our knowledge this is the first study that analyzes the impact on the functional independence of two symptoms very commonly experienced in subjects with motor incomplete SCI. Our findings did not confirm the hypothesis that pain and fatigue interfere in the ability of motor incomplete SCI subjects to perform independently their activities of daily living. Specifically, we did not find significant differences in the functional independence when we compared the FIM motor in both groups; pain vs. no pain, and fatigue vs. no fatigue.

These findings were consistent with previous studies examining the impact of pain in SCI. Ballinger et. al., [27] used the FIM to examine the functional ability of 89 adult with traumatic tetraplegia and paraplegia and found that shoulder pain was unrelated to the functional limitation. Other study found similar results using the Spinal Cord Independence Measure (SCIM) to examine the functional activity [9]. A difference with these studies, we assessed the intensity of the global pain in motor incomplete SCI (AIS C and D). Sillverskiold and Waters [28] reported that $84 \%$ of the quadriplegics subjects with shoulder pain had either moderate or severe functional
Table 2: Summary of Cases.

\begin{tabular}{|c|c|c|c|}
\hline & $\begin{array}{c}\text { Sample Size } \\
\mathbf{n}(\%)\end{array}$ & $\begin{array}{c}\text { Variable } \\
\text { Mean }\end{array}$ & $\begin{array}{c}\text { FIM Motor Median } \\
\text { (range) }\end{array}$ \\
\hline Fatige & $22(30 \%)$ & 4,59 & $80(19-89)$ \\
\hline $\begin{array}{c}\text { Has Fatigue } \\
\text { fatigue }\end{array}$ & $52(70 \%)$ & 2,34 & $83(13-91)$ \\
\hline Pain & & & $p 0.874$ \\
\hline Has Pain & $25(34 \%)$ & 5,88 & $80(19-91)$ \\
\hline Does not have Pain & $49(66 \%)$ & 0,47 & $83(13-91)$ \\
\hline & & & $p 0.363$ \\
\hline
\end{tabular}

Note: Values of Median (Range).

Abbreviation: FSS: Fatigue Severity Scale; VAS: Visual Analogue Scale; FIM: Functional Independence Measurement.

*Statistically Significant Difference at the $<0.05$.

disability during the first six months after SCI. However, this study evaluated the functional limitation using not standardized measurements of function.

On the other hand, our results showed that fatigue not modify the functional independence in motor incomplete spinal cord subjects. These findings could be a complement to the limited information that exists in the study of the impact of fatigue in subjects after the spinal cord injury. Previous studies reported that elevated levels of fatigue were associated with significantly reduced in quality of life $[7,10]$.

Alschuler et al. [8] measured the relationship between the pain/fatigue and the physical functioning in SCI subjects, finding that higher pain levels were associated with less physical activity. This research used the Patient-Reported Outcomes Measurement Information System (PROMIS) to measure physical functioning; however this is not a specific functional independence scale.

Related to the prevalence, we found that fatigue and pain are common with $30 \%$ of the sample reporting high fatigue levels and $34 \%$ reporting high pain levels. The prevalence of fatigue in our participants was lower compared with the $57 \%$ previously reported by Fawkes-Kirby [5], nevertheless our sample showed elevated levels of fatigue compared with the able-bodied subjects [7]. The prevalence of pain found was within the parameters reported by Jensen [13].

In our knowledge, this is the first research who studies the pain and the fatigue in these specific SCI group. Both symptoms showed to be frequent and lead to negative health results reducing the quality of life, therefore it is important to take care of them in the rehabilitation programs $[5,10,13]$.

In summary, the presence of significative fatigue and pain in subjects with motor incomplete SCI was unrelated to any of the functional limitation measures. This might be explained in part by the fact that the subjects analyzed have to maintain self-independence regardless the fatigue and the pain. They have to maintain their occupational engagement and physical activity even if they have both symptoms $[9,29]$.

There were limitations in this study. First, the sample size was relative small, particularly in the subgroups with pain and fatigue, which could have influenced the results. Second, fatigue and pain were measured using self-reported instruments, which may lead to 
overestimation or underestimation of the incidence. Futures studies would increase the simple size, in order to analyze both symptoms simultaneously and their incidence in functional independence.

\section{Conclusion}

Pain and fatigue are relatively prevalent symptoms in persons with motor incomplete SCI; however these symptoms did not interfere with our participant's ability to perform activities of daily living independently.

\section{References}

1. Hadjimichael O, Vollmer T, Oleen-Burkey M. North American Research Committee on Multiple Sclerosis. Fatigue characteristics in multiple sclerosis: the North American Research Committee on Multiple Sclerosis (NARCOMS) survey. Health Qual Life Outcomes. 2008; 6: 100.

2. Levine J, Greenwald. Fatigue in Parkinson disease, stroke, and traumatic brain injury. Phys Med Rehabil Clin N Am. 2009; 20: 347-361.

3. Herlofson K, Larsen JP. The influence of fatigue on health-related quality of life in patients with Parkinson's disease. Acta Neurol Scand. 2003; 107: 1-6.

4. McGeough E, Pollock A, Smith LN, Dennis M, Sharpe M, Lewis S, et al Interventions for post-stroke fatigue. Cochrane Database Syst Rev. 2009; 8: CD007030.

5. Fawkes-Kirby TM, Wheeler MA, Anton HA, Miller WC, Townson AF. Clinical correlates of fatigue in spinal cord injury. Spinal Cord. 2008; 46: 21-25.

6. Hammell KW, Miller WC, Forwell SJ, Forman BE, Jacobsen BA. Fatigue and spinal cord injury, a qualitative analysis. Spinal Cord. 2009; 47: 44-49.

7. Wijesuriya N, Tran $\mathrm{Y}$, Middleton J, Craig A. Impact of fatigue on the healthrelated quality of life in persons with spinal cord injury. Arch Phys Med Rehabil. 2012; 93: 319-324.

8. Alschuler KN, Jensen MP, Sullivan-Singh SJ, Borson S, Smith AE, Molton IR. The association of age, pain, and fatigue with physical functioning and depressive symptoms in persons with spinal cord injury. J Spinal Cord Med. 2013; 36: 483-491.

9. Wang JC, Chan RC, Tsai YA, Huang WC, Cheng $\mathrm{H}$, Wu HL, et al. The influence of shoulder pain on functional limitation, perceived health, and depressive mood in patients with traumatic paraplegia. J Spinal Cord Med. 2015; 38: 587-592.

10. Hammell KW, Miller WC, Forwell SJ, Forman BE, Jacobsen BA. Managing fatigue following spinal cord injury: a qualitative exploration. Disabil Rehabil. 2009; 31: 1437-1445

11. Rodrigues D, Tran Y, Guest R, Middleton J, Craig A. Influence of neurological lesion level on heart rate variability and fatigue in adults with spinal cord injury. Spinal Cord. 2016; 54: 292-297.

12. Lidal IB, Jensen AE, Larsen TW, Stanghelle JK. Fatigue in persons who lived with spinal cord injury for $>20$ years. Spinal Cord. 2013; 51: 103-108.

13. Jensen MP, Kuehn CM, Amtmann D, Cardenas DD. Symptom burden in persons with spinal cord injury. Arch Phys Med Rehabil. 2007; 88: 638-645.

14. Freixes $O$, Rivas ME, Agrati PE, Bochkezanian $V$, Waldman SV, Olmos LE. Fatigue level in spinal cord injury AIS D community ambulatory subjects. Spinal Cord. 2012; 50: 422-425.
15. Dijkers M, Bryce T, Zanca J. Prevalence of chronic pain after traumatic spinal cordinjury: a systematic review. J Rehabil Res Dev. 2009; 46: 13-29.

16. Johnson RL, Gerhart KA, McCray J, Menconi JC, Whiteneck GG. Secondary conditions following spinal cord injury in a population-based sample. Spinal Cord. 1998; 36: 45-50.

17. Turner JA, Cardenas DD, Warms CA, McClellan CB. Chronic pain associated with spinal cord injuries: a community survey. Arch Phys Med Rehabil. 2001; 82: 501-509.

18. Widerström-Noga EG, Felipe-Cuervo E, Yezierski RP. Chronic pain after spinal injury: interference with sleep and daily activities. Arch Phys Med Rehabil. 2001; 82: 1571-1577.

19. DeVivo MJ, Chen Y. Trends in new injuries, prevalent cases, and aging with spinal cord injury. Arch Phys Med Rehabil. 2011; 92: 332-328.

20. Paolinelli C, Gonzalez P, Doniez ME, Donoso T, Salinas V. Instrument for the functional evaluation of disability rehabilitation. Study on the reliability and clinical experience with the use of functional independence measure. Rev Med Chil. 2001; 129: 23-31.

21. Dodds TA, Matrin DP, Stolov WC, Deyo RA. A validation of the functional independence measurement and its performance among rehabilitation inpatients. Arch Phys Med Rehabil. 1993; 74: 531-536.

22. Karamehmetoglu SS, Karacan I, Elbasi N, Demirel G, Koyuncu H, Dosoglu M. The Functional Independence Measure in spinal cord injured patients: comparison of questioning with observational rating. Spinal Cord. 1997; 35: 22-25.

23. Anton HA, Miller WC, Townson AF. Measuring fatigue in persons with spinal cord injury. Arch Phys Med Rehabil. 2008; 89: 538-542.

24. Imam B, Anton HA, Miller WC. Measurement properties of a telephone version of the Modified Fatigue Impact Scale among individuals with a traumatic spinal cord injury. Spinal Cord. 2012; 50: 920-924.

25. Krupp LB, LaRocca NG, Muir-Nash J, Steinberg AD. The fatigue severity scale. Application to patients with multiple sclerosis and systemic lupus erythematosus. Arch Neurol. 1989; 46: 1121-1123.

26. Hawker GA, Mian S, Kendzerska T, French M. Measures of adult pain: Visual Analog Scale for Pain (VAS Pain), Numeric Rating Scale for Pain (NRS Pain), McGill Pain Questionnaire (MPQ), Short-Form McGill Pain Questionnaire (SF-MPQ), Chronic Pain Grade Scale (CPGS), Short Form-36 Bodily Pain Scale (SF-36 BPS), and Measure of Intermittent and Constant Osteoarthritis Pain (ICOAP). Arthritis Care Res. 2011; 63: 240-252.

27. Ballinger DA, Rintala DH, Hart KA. The Relation of shoulder pain and range of motion problems to functional limitations, disability, and perceived health of men with spinal cord injury. A multifaceted longitudinal study. Arch Phys Med Rehabil. 2000; 81: 1575-1581.

28. Silfverskiold J, Waters RL. Shoulder pain and functional disability in spinal cord injury patients. Clin Orthop Relat Res. 1991; 272: 141-145.

29. Silvestri J. Effects of chronic shoulder pain on quality of life and occupational engagement in the population with chronic spinal cord injury: preparing for the best outcomes with occupational therapy. Disabil Rehabil. 2016; 1-9.
Phys Med Rehabil Int - Volume 5 Issue 3 - 2018 ISSN : 2471-0377 | www.austinpublishing group.com Gatti et al. (C) All rights are reserved
Citation: Fernández SA, Gatti MA, Buffetti E, Freixes O, Bonetto M, Waldman SV, et al. Does Pain and Fatigue Interfere in the Independence of People with Incomplete Spinal Cord Injury?. Phys Med Rehabil Int. 2018; 5(3): 1150. 